\title{
A EFICACIA DAS TECNICAS COGNITIVAS E COMPORTAMENTAIS NOS TRANSTORNOS SEXUAIS
}

\author{
Helen Magda Rodrigues Camargos ${ }^{1}$ \\ Résia Silva de Morais ${ }^{2}$
}

INTRODUÇÃO: Técnicas Cognitivas Comportamentais (TCC's) referem-se a um conjunto de intervenções que podem ser adotadas para o tratamento das dificuldades sexuais e envolvem psicoeducação, aconselhamento, permissão sexual, assertividade, treino de comunicação, atividades de exploração, conscientização corporal, de modo a combinar intervenções médicas à experiência sexual como um todo. OBJETIVO: O presente estudo objetivo descrever possíveis intervenções a serem utilizadas para a aplicação de técnicas cognitivas e comportamentais nos transtornos sexuais, de forma a observar a sua eficácia para este fim. MÉTODO: Foi realizada uma revisão da literatura, por meio da coleta de dados em artigos indexados nas bases Scielo e Pepsic. Na busca dos artigos consideraram-se os descritores: "terapia sexual" e "terapia cognitivo-comportamental" e "disfunções sexuais". Optou-se por textos nacionais publicados entre 2000 e 2016, visando concepções que dialogassem com a cultura brasileira. Foram selecionadas 15 referencias nacionais em relação ao tema. RESULTADOS: As técnicas de TCC para transtornos sexuais, quando norteadas para atender todas as vias de ação de relaxamento baseadas nas orientações cognitivas, autonômicas e musculares e nos procedimentos terapêuticos adequados, contribuem para resultados mais efetivos. Ao partir desta premissa, tem-se a oportunidade de se trabalhar em totalidade as distorções procedentes de todos os lados possíveis, vez que a estrutura física e mental necessita estar em harmonia para que se proponha um trabalho integral e, portanto, terapias sexuais bem-sucedidas. Pensamentos inconscientes de forma espontânea decodificam circunstâncias, e normalmente as pessoas acolhem estes pensamentos automáticos sem que estejam hábeis a realizar uma monitorização adequada dos mesmos. $\mathrm{E}$ a terapia sexual contribui para que o paciente seja capaz de conhecer e monitorar pensamentos que os levam a disfunção sexual. Neste processo, o terapeuta deve ter pleno

\footnotetext{
${ }^{1}$ Acadêmica do curso de psicologia da Faculdade de Patos de Minas - FPM. E-mail: helenmagda@hotmail.com

${ }^{2}$ Docente do departamento de psicologia da Faculdade Patos de Minas - FPM.
} 
conhecimento das abordagens farmacológicas e psicoterápicas possíveis de serem utilizadas, devendo estar sempre orientado para a fisiologia da resposta sexual. CONSIDERAÇÕES FINAIS: A TCC sugere ser eficaz para transtornos sexuais devido a contribuir para modificar condutas inadequadas, ao centrar-se nas questões evidenciadas pelo paciente quando este busca a terapia, pois a sua finalidade é contribuir para que a pessoa tenha a chance de apreender novas formas de viver mediante a promoção de mudanças necessárias. As técnicas adotadas nas terapias sexuais se estabelecem por meio da uma colaboração entre o terapeuta e o paciente, cujas estratégias são orientadas para a superação de problemas devendo ser projetadas conjuntamente. A base do tratamento proposto com a TCC é o cerne do sofrimento do paciente, em outros termos, parte-se das distorções que estão ocorrendo no modo que a pessoa consegue avaliar a si mesmo e a realidade em que se encontra inserido. Logo, o que se trabalha é a possibilidade de a pessoa alcançar uma posição mais confortável diante das próprias condições por ela criadas.

Palavras-chave: Distorções Cognitivas; Psicoterapias; Procedimentos terapêuticos. 